Research article

Open Access

\title{
Stability-Indicating HPLC Method for Posaconazole Bulk Assay
}

\author{
Cássia V. GARCIA * ${ }^{1}$, Gislaine R. Costa ${ }^{2}$, Andreas S. L. Mendez ${ }^{2}$ \\ ${ }^{1}$ Departamento de Produção e Controle de Medicamentos, Faculdade de Farmácia, Universidade Federal \\ do Rio Grande do Sul (UFRGS). Av. Ipiranga, 2752. Sala 406. CEP 90610-000, Porto Alegre/RS, Brazil. \\ ${ }^{2}$ Laboratório de Desenvolvimento e Controle de Qualidade de Medicamentos, Universidade Federal do \\ Pampa (UNIPAMPA). BR 472 km 585. CEP 97500-970, Uruguaiana/RS, Brazil \\ * Corresponding author. E-mail: cassiavgarcia@yahoo.com.br (C. V. Garcia)
}

Sci Pharm. 2012; 80: 317-327

doi:10.3797/scipharm.1111-11

Published: $\quad$ March $12^{\text {th }} 2012$

Accepted: $\quad$ March $12^{\text {th }} 2012$

Received: $\quad$ November $11^{\text {th }} 2011$

This article is available from: http://dx.doi.org/10.3797/scipharm.1111-11

(c) Garcia et al.; licensee Österreichische Apotheker-Verlagsgesellschaft m. b. H., Vienna, Austria.

This is an Open Access article distributed under the terms of the Creative Commons Attribution License (http://creativecommons.org/licenses/by/3.0/), which permits unrestricted use, distribution, and reproduction in any medium, provided the original work is properly cited.

\begin{abstract}
A stability-indicating liquid chromatographic (LC) method was developed for the determination of posaconazole in bulk. Chromatographic separation was achieved using an isocratic elution in a reversed-phase system, with a mobile phase composed of methanol-water $(75: 25, \mathrm{v} / \mathrm{v})$, at $1.0 \mathrm{~mL} \mathrm{~min}^{-1}$ flow. Samples were exposed to degradation under thermal, oxidative and acid/basic conditions, and no interference in the analysis was observed. System suitability was evaluated and results were satisfactory $(N=4,900.00$ tailing factor 1.04 ; RSD between injections $=0.65$ ). The retention time of posaconazole was about $8.5 \mathrm{~min}$ and the method was validated within the concentration range 5-60 $\mathrm{\mu g}$ $\mathrm{mL}^{-1}(\mathrm{r}=0.9996)$. Adequate results were obtained for repeatability (RSD \% = 0.86-1.22), inter-day precision (RSD \% = 1.21) and accuracy (98.13\% mean recovery). Robustness was also determined to be satisfactory after evaluation. The proposed method was successfully applied to posaconazole bulk quantification, showing the method is useful for determination of the drug in routine analysis.
\end{abstract}

\section{Keywords}

Posaconazole $\bullet$ Triazoles $• \mathrm{HPLC} \cdot$ Stability-indicating assay $\bullet$ Bulk $\bullet$ Stress conditions

\section{Introduction}

Throughout the past decades, a significant increase in the incidence of invasive fungal infections has been observed, mainly because of the high number of immunocompromised 
patients, such as cancer patients, those with acquired immunodeficiency syndrome and haemopoietic stem-cell transplant recipients $[1,2]$. The number of agents available to treat fungal infections has increased by $30 \%$ since the year 2000 . However, differences in antifungal spectrum of activity, bioavailability, formulation, drug interactions and side effects make necessary a detailed knowledge about each drug class [3, 4].

Posaconazole, 4-\{4-[4-(4-\{[(3R,5R)-5-(2,4-difluorophenyl)-5-(1H-1,2,4-triazol-1-ylmethyl)tetrahydrofuran-3-yl]methoxy\}phenyl)piperazin-1-yl]phenyl\}-2-[(1S,2S)-1-ethyl-2-hydroxypropyl]-2,4-dihydro-3H-1,2,4-triazol-3-one (Fig. 1), is a triazole antifungal drug, approved by the FDA in 2006 and characterized for the broader spectra of action between triazoles, besides the less potential of interactions [3]. It is the first azole agent to demonstrate activity against the zygomycetes, a difficult-to-treat family that includes Mucor and Rhizopus species [2].

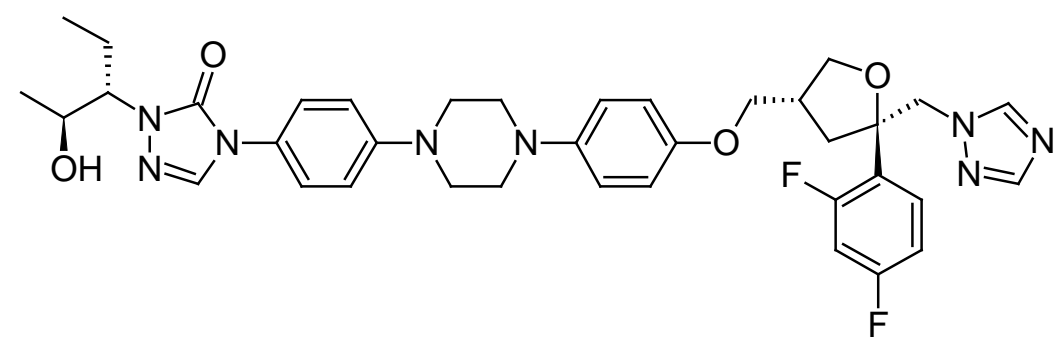

Fig. 1. Chemical structure of posaconazole.

Literature presents some works related to posaconazole assay in biological fluids applying mainly chromatographic methods [5-11]. Kim et al. (2000) [5] validated a reversed-phase HPLC method, using $0.09 \mathrm{M}$ ammonium phosphate monobasic acetonitrile- triethylamine (530:470:0.5 v/v/v) mobile phase for pharmacokinetics studies in dog serum with limit of quantification of $0.05 \mu \mathrm{g} \mathrm{ml}^{-1}$. In 2003 [6], the same group evaluated the presence of posaconazole active metabolites in human plasma by HPLC and microbiological assay, applying a mobile phase composed of $0.09 \mathrm{M}$ ammonium phosphate buffer $(\mathrm{pH} 4.5)-$ acetonitrile-methylene chloride-triethylamine (1060:940:10:1 v/v), a $\mathrm{C}_{18}$ column and 262 $\mathrm{nm}$ UV detection for the chromatographic method, and Candida pseudotropicalis ATCC 46764 for agar diffusion method. No active metabolite was found. LC-MS/MS methods were also developed [7,9] to determine posaconazole in human plasma in the concentration range of 5.0 to $5000 \mathrm{ng} \mathrm{ml}^{-1}$. For the first method [7], the chromatographic conditions included a gradient mobile phase program, $\mathrm{C}_{18}$ column and sample ionization by atmospheric pressure chemical ionization (APCI) in the positive-ion mode. For the last method [9], a triple quadrupole equipment and sample ionization using TurbolonSpray ${ }^{\circledR}$ probe in positive-ion mode were used. Both demonstrated to be accurate and sensitive. Considering concomitant analysis of other azoles drugs and posaconazole in human plasma/serum, some works were published using liquid chromatography with UV and MS/MS detection, respectively $[8,10]$. The mobile phases were composed of buffers and organic solvents in both cases. Ekiert et al. [11] made a review about the chromatographic and electrophoretic methods applied to azoles determination, including posaconazole. It is possible to observe the small number of works related and the lack of studies about other matrixes than biological fluids. 
Considering the analysis in bulk or pharmaceutical products, there is no work published and no monograph available in pharmacopoeias. So, the objective of this work is to develop and validate a stability-indicating high performance liquid chromatographic method for determination of posaconazole in bulk, according to official guidelines [12-14], with no necessity of buffers in the mobile phase.

\section{Results and Discussion}

A simple, rapid and practical analytical procedure by LC was developed and validated for the determination of posaconazole in bulk. To show the capability to determine the drug in the presence of eventual degradation products, a forced degradation study was performed applying different degradation conditions [15].

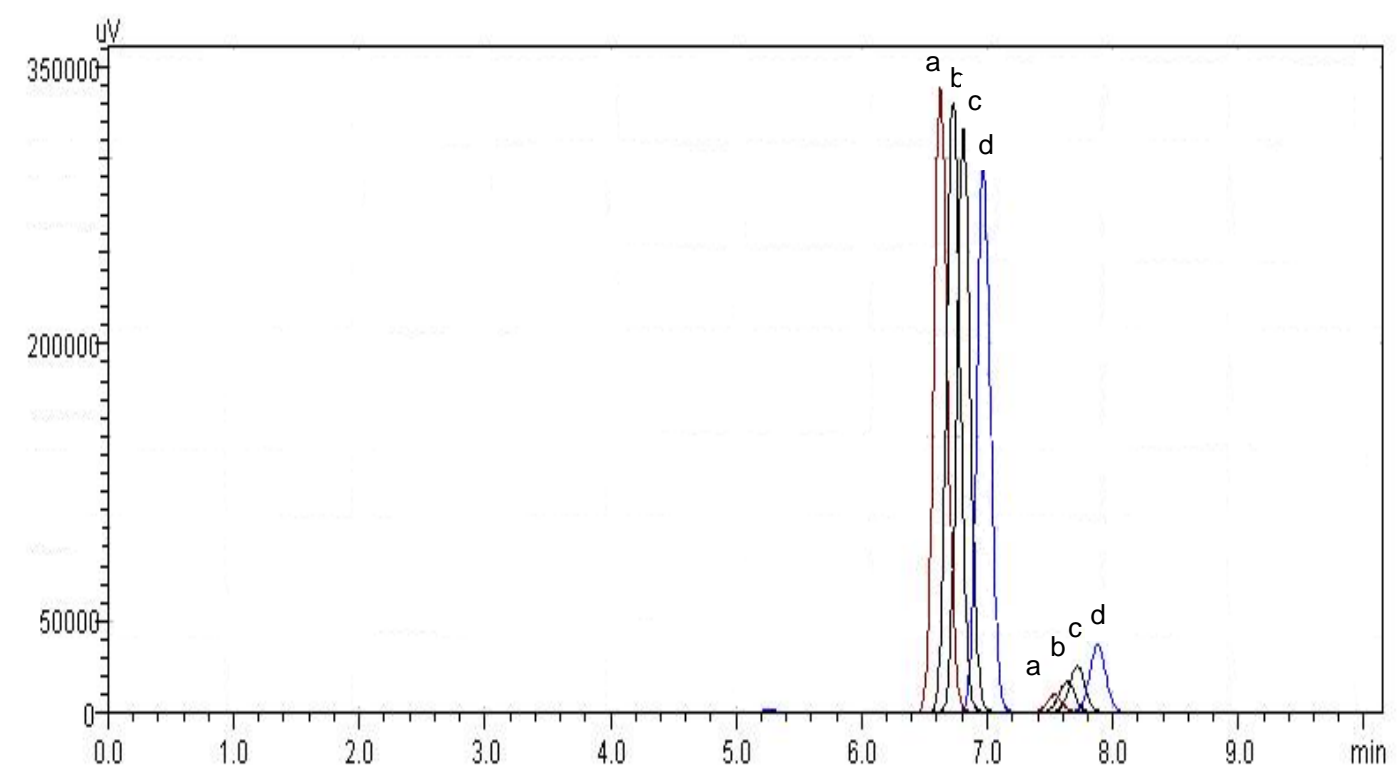

Fig. 2. Chromatograms of posaconazole standard solution using acetonitrile:water (60:40, v/v) as mobile phase, $\mathrm{C}_{8}$ column. (a) time zero, (b) 10 min later, (c) 20 min later, (d) 30 min later. For better evaluation, the chromatograms were dislocated.

In this work, the analytical parameters were studied to demonstrate that the assay is reliable for quantification of the drug. Considering previous works describing analytical methods for biological fluids and also some works for other triazoles [11], the focus was to develop a simple and fast method, using columns and solvents freely available, which could be easily adopted in routine quality control. For the development of the method, preliminary studies were performed using different mobile phase composition (acetonitrile or methanol as organic solvents mixed with ultrapure water) and serial proportions, different reverse phase columns $\left(\mathrm{C}_{8}\right.$ and $\left.\mathrm{C}_{18}\right)$ and concentrations of drug. The results of this step demonstrated $\mathrm{C}_{8}$ column had a better efficiency than $\mathrm{C}_{18}$ one, according to theoretical plates results ( $\mathrm{N}$ approximately 2350 and 4900, respectively). As organic solvent, acetonitrile was not considered adequate for mobile phase composition, since degradation of the drug was observed in the chromatographic runs throughout the day when using the 60:40 v/v proportion. One main degradation product was detected at 7.5 
min (Fig. 2). About 13\% of degradation could be seen in $30 \mathrm{~min}$. This data was unexpected, since there are other methods which use this solvent. No satisfactory explanation was found, and thus, methanol was chosen. The preliminary studies about concentration demonstrated the range 5-60 $\mathrm{\mu g} \mathrm{mL}^{-1}$ would be adequate, which was confirmed by the validation procedure later. The wavelength of detection could be monitored by PDA detector and $260 \mathrm{~nm}$ was selected (Fig. 3). The injection volume adopted was the usual $20 \mu \mathrm{L}$ used for analytical purposes. After these studies, the chromatographic conditions were established and the validation procedure performed. Under these conditions, the retention time for posaconazole was 8.5 min (Fig. 4), which is adequate for routine analysis. The RSD value calculated for the peak area was $0.65 \%$, indicating the reproducibility for this parameter. The tailing factor observed was 1.04, showing the peak symmetry. Theoretical plates of chromatographic separation were $4,900.00$ with an RSD of $0.31 \%$.

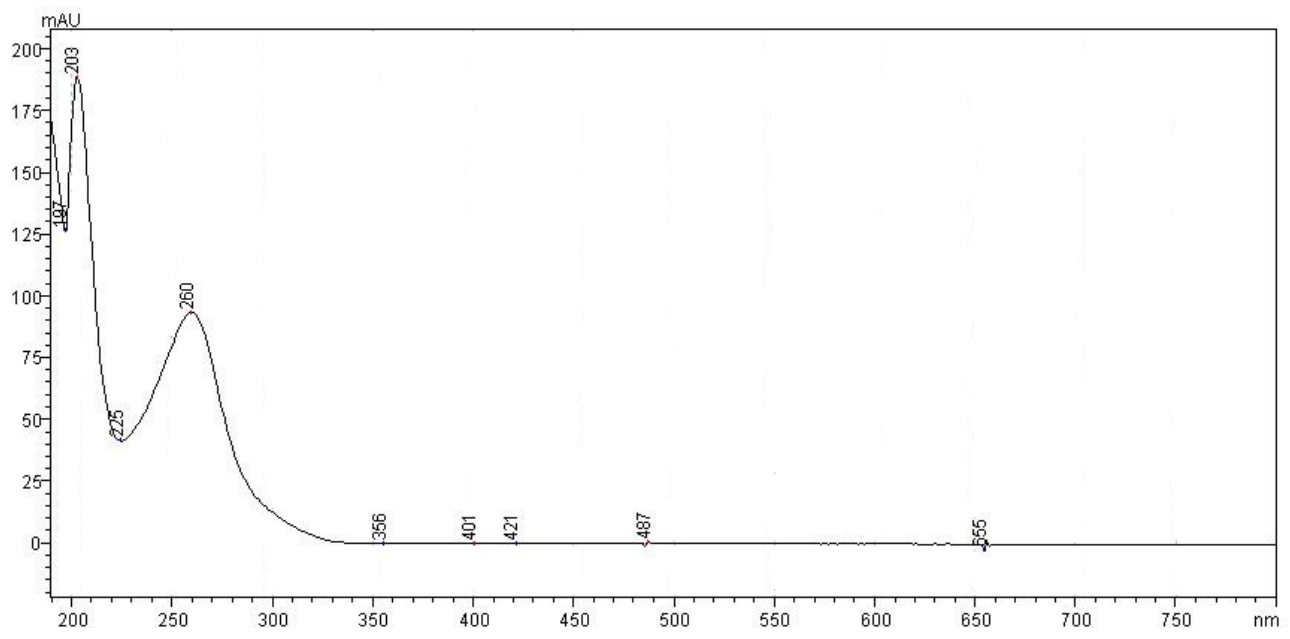

Fig. 3. UV spectrum of posaconazole obtained by PDA detector.

\section{Validation procedure}

\section{Specificity}

The LC chromatograms for posaconazole and degraded solutions are shown in Fig. 5. The drug was detected at $8.5 \mathrm{~min}$, and only under oxidative condition, a degradation product was detected (retention time of $4.4 \mathrm{~min}$ ) (Fig. 5b). The remaining amount of posaconazole after 10 days was $89.2 \%$. For the other degradation conditions no degradation product was observed after 10 days of exposition. However, under acid condition, a small percentage of drug degradation was observed (2.4\%). The analysis of the chromatograms of the degraded samples and the application of the peak purity tool (Fig. 6), which demonstrated posaconazole peak was pure in all situations, allowed us to conclude that degradation products do not interfere with the analysis of the drug, indicating that the developed LC method was selective for the determination of this antifungal in bulk. 

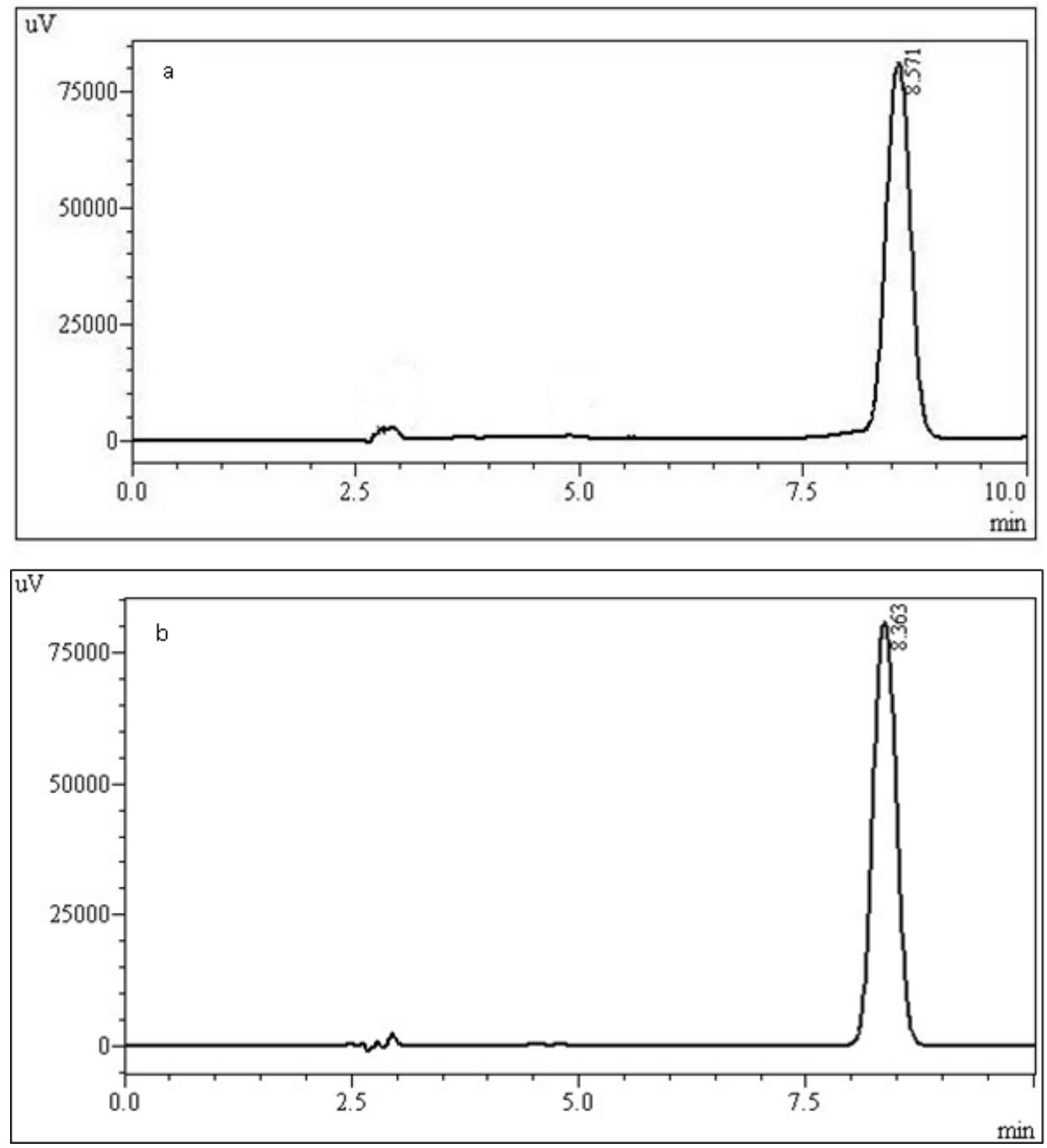

Fig. 4. Representative chromatograms of posaconazole standard solution (a) and bulk sample (b), both at concentration of $30 \mu \mathrm{g} \mathrm{mL}^{-1}$.

\section{Linearity}

To assess linearity, three standards curves for posaconazole were constructed by plotting concentration of drug $(x)$ versus peak area $(y)$. Over the concentration range of 5-60 $\mu \mathrm{g}$ $\mathrm{mL}^{-1}$, the slope and the intercept obtained were 43366 and -22157 , respectively, and the correlation coefficient was 0.9996, indicating an excellent correlation between the parameters cited above. The statistical results obtained from ANOVA showed that the regression equation was linear $\left(F_{\text {calculated }}=53497>F_{\text {critical }}=4.60 ; p=0.05\right)$ with no deviation from linearity $\left(F_{\text {calculated }}=1.73<F_{\text {critical }}=2.96 ; p=0.05\right)$.

\section{Precision}

The precision results are shown in Table 1 . The low values of RSD for both the repeatability and the intermediate precision demonstrate the good precision of the method proposed. 
Tab. 1. Precision results for chromatographic posaconazole bulk assay.

\begin{tabular}{lcc}
\hline & \multicolumn{2}{c}{ Intra-day precision } \\
\cline { 2 - 3 } & Amount* (\%) & RSD (\%) \\
\hline Day 1 & 99.39 & 0.88 \\
Day 2 & 101.40 & 1.22 \\
Day 3 & 99.61 & 0.86 \\
Inter-day precision & 100.01 & 1.21 \\
\hline
\end{tabular}

\section{Accuracy}

The accuracy results are summarized in Table 2. Mean recovery for posaconazole reference standard was between 98.13\% $(n=3)$, indicating that the developed method was accurate for determination of the drug.

Tab. 2. Results from accuracy evaluation of the chromatographic posaconazole bulk assay.

\begin{tabular}{|c|c|c|c|c|}
\hline Level & $\begin{array}{l}\text { Amount added } \\
\left(\mu \mathrm{g} \mathrm{mL} \mathrm{mL}^{-1}\right)\end{array}$ & $\begin{array}{l}\text { Amount found } \\
\left(\mu \mathrm{g} \mathrm{mL}^{-1}\right)\end{array}$ & $\begin{array}{c}\text { Mean of recovery* } \\
(\%)\end{array}$ & $\begin{array}{l}\text { RSD } \\
(\%)\end{array}$ \\
\hline R1 & 10.0 & 9.90 & 98.95 & 1.17 \\
\hline $\mathrm{R} 2$ & 20.0 & 19.46 & 97.30 & 1.06 \\
\hline R3 & 25.0 & 24.53 & 98.13 & 0.71 \\
\hline
\end{tabular}

\section{Robustness}

By evaluating the results obtained from the analysis performed under all the deliberate variations in chromatographic conditions, the developed LC method indicated good performance, demonstrating to be robust and reliable in the determination of the drug. The chromatographic pattern was maintained in all conditions with small changes in the retention time (mainly when the mobile phase proportion was modified). The modification

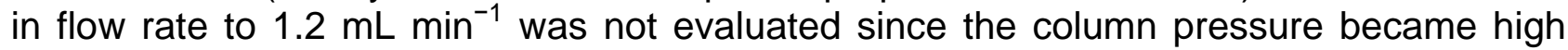
and could damage the system. Despite retention time, the quantitation of posaconazole was maintained in all conditions, with low values of RSD. The results are shown in Tab. 3.

Tab. 3. Results from robustness test of chromatographic posaconazole bulk assay.

\begin{tabular}{lcccccc}
\hline & \multicolumn{6}{c}{ Robustness condition } \\
\cline { 2 - 7 } & $\begin{array}{c}\text { Nominal } \\
\text { condition }\end{array}$ & $\begin{array}{c}\text { Mobile phase } \\
\text { proportion (\%) }\end{array}$ & Wavelength (nm) & $\begin{array}{c}\text { Flow rate } \\
\text { (mL min } \text { m }^{-1} \text { ) }\end{array}$ \\
\cline { 2 - 7 } & & 77 & 73 & 258 & 262 & 0.8 \\
\hline Amount (\%) & 100.21 & 100.7 & 100.0 & 99.82 & 99.93 & 99.61 \\
RSD (\%) & & 1.15 & 0.98 & 1.04 & 0.92 & 1.16 \\
Retention time (min) & 8.5 & 7.23 & 10.95 & 8.5 & 8.5 & 10.85 \\
Theoretical plates & $4,900.0$ & $4,742.0$ & $4,731.7$ & $4,911.7$ & $4,906.4$ & $4,788.5$ \\
\hline
\end{tabular}



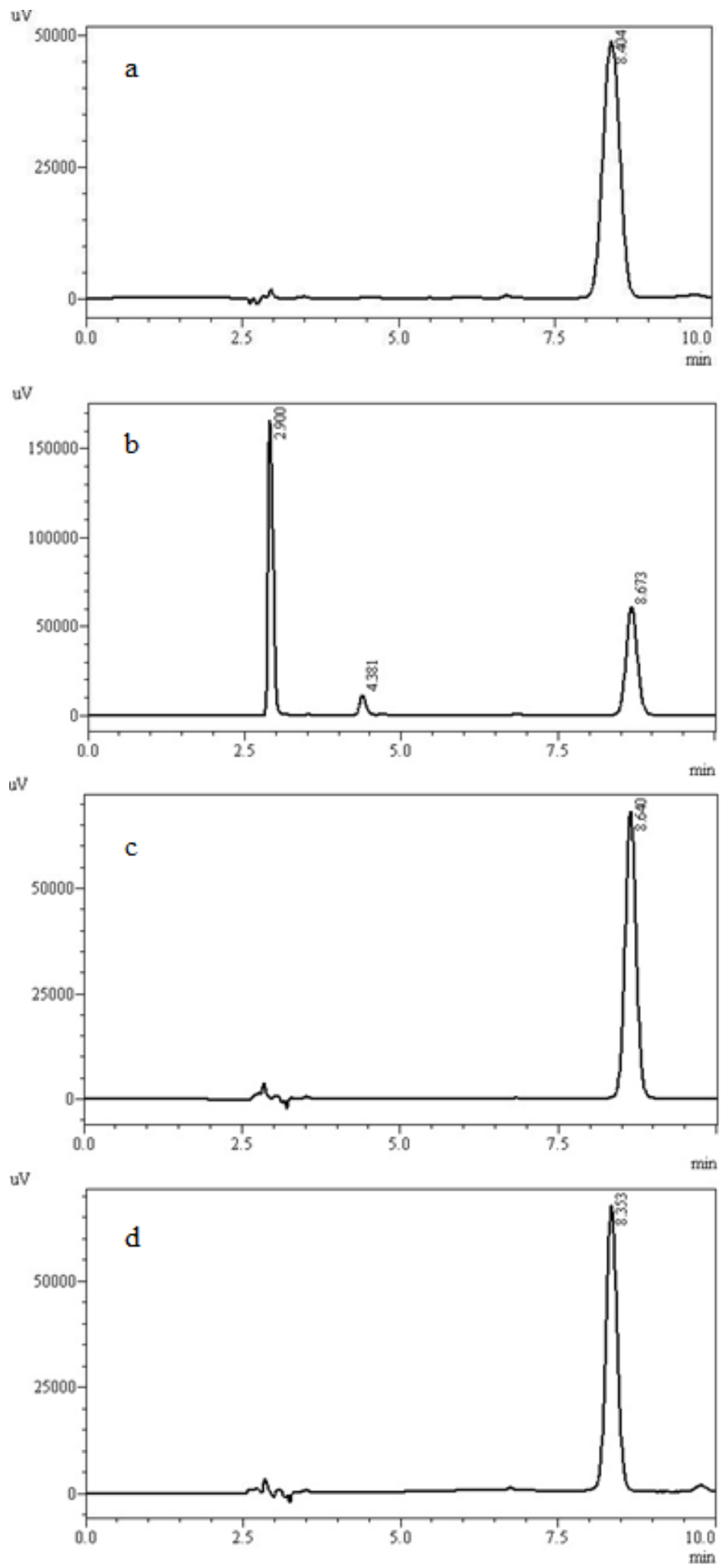

Fig. 5. LC chromatograms of posaconazole degraded samples. (a) posaconazole sample solution after thermal degradation $\left(40^{\circ} \mathrm{C}, 10\right.$ days); (b) posaconazole sample solution after oxidative degradation $\left(\mathrm{H}_{2} \mathrm{O}_{2} 3 \%, 10\right.$ days); (c) posaconazole sample solution after acid degradation ( $\mathrm{HCl} \mathrm{0,1} \mathrm{N,10} \mathrm{days);} \mathrm{(d)}$ posaconazole sample solution after basic degradation ( $\mathrm{NaOH} 0,1 \mathrm{~N}, 10$ days). 


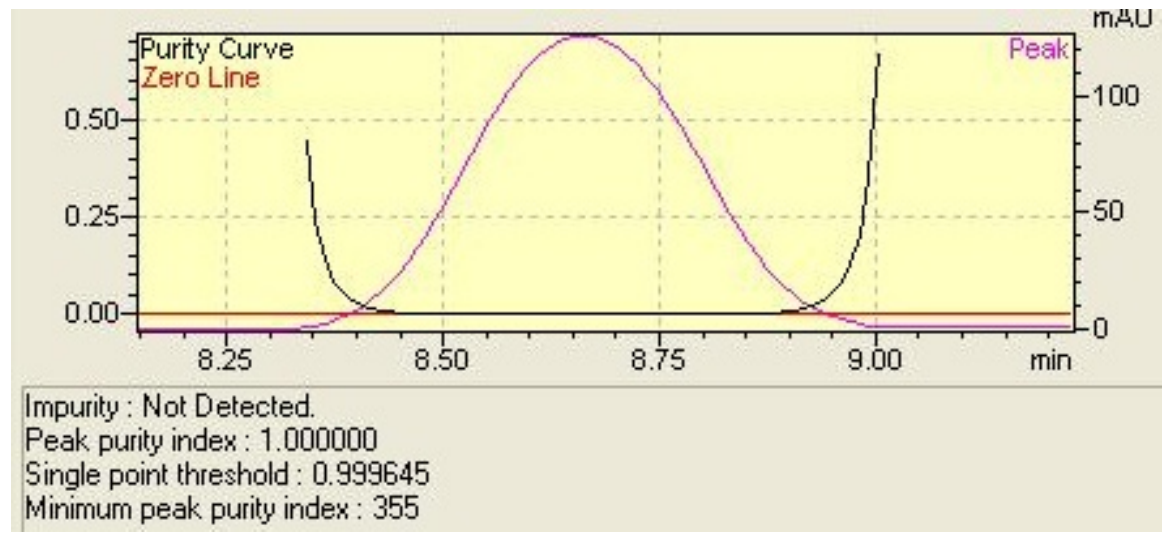

Fig. 6. Representation of peak purity curve of posaconazole peak in degradation studies.

\section{Experimental}

\section{Chemicals}

Posaconazole reference standard (99.9\%) and bulk were purchased from ACC Corp. (San Diego, USA). The reagents used were of analytical grade, and all solvents were of HPLC grade (Tedia, Fairfield, OH, USA). Purified water was prepared using Milli-Q Plus ${ }^{\circledR}$ (Millipore, Bedford, USA).

\section{Apparatus}

The LC method was performed on a Shimadzu Prominence Liquid Chromatograph, equipped with a LC-20AT pump, SIL-20A auto sampler, SPD-20AT PDA detector and CTO-20A column oven (Shimadzu, Kyoto, Japan). LC Solution V. 1.24 SP1 system software was used to control the equipment and to calculate data and responses from the LC system. To perform the thermal degradation, a dry air oven (Nova Ética ${ }^{\circledR}$, São Paulo, Brazil) was used.

\section{Chromatographic conditions}

Posaconazole was eluted isocratically with a flow rate of $1.0 \mathrm{~mL} \mathrm{~min}^{-1}$ using a mobile phase consisting of methanol-water $(75: 25 ; \mathrm{v} / \mathrm{v})$. The wavelength of the PDA detector was set at $260 \mathrm{~nm}$. The mobile phase was prepared daily, filtered through a $0.45 \mu \mathrm{m}$ membrane filter (Millipore) and sonicated before use. A Shim-pack $\mathrm{C}_{8}(250 \times 4.6 \mathrm{~mm} ; 5 \mu \mathrm{m}$ - Shimadzu, Kyoto, Japan) was used. The HPLC system was operated at $25 \pm 1^{\circ} \mathrm{C}$. The injection volume was $20 \mu \mathrm{L}$.

\section{Preparation of solutions}

Posaconazole reference standard was accurately weighed and dissolved in a $100 \mathrm{~mL}$ volumetric flask with methanol to obtain a concentration of $100.0 \mu \mathrm{g} \mathrm{mL}^{-1}$. This solution was diluted in the same solvent to yield a final concentration of $30.0 \mu \mathrm{g} \mathrm{mL}^{-1}$. 
For bulk, $10 \mathrm{mg}$ of posaconazole was transferred to a $100 \mathrm{~mL}$ volumetric flask and dissolved in methanol for a concentration of $100 \mu \mathrm{g} \mathrm{mL}^{-1}$. An aliquot of this solution was diluted with the same solvent until the concentration was $30 \mu \mathrm{g} \mathrm{mL}^{-1}$. Both solutions were filtered through a $0.45 \mu \mathrm{m}$ membrane filter (Millipore) before the injection.

\section{System suitability}

For system suitability evaluation, a standard solution containing $30 \mu \mathrm{gL}^{-1}$ of posaconazole was injected six times. Chromatographic parameters including injection repeatability, retention time, theoretical plates and tailing factor were measured.

\section{Validation procedure}

The chromatographic method was validated by evaluation of the analytical parameters including specificity, linearity, precision, accuracy and robustness $[12,13]$. The stabilityindicating capability was determined by forced degradation conditions, including testing heat, oxidation and acid and basic degradation [15].

\section{Specificity}

The specificity was evaluated through the analysis of a posaconazole bulk solution (100 $\mu \mathrm{g}$ $\mathrm{mL}^{-1}$ ) in methanol, which was exposed to accelerated degradation conditions (see below). All results were compared to a reference solution, prepared in the same day.

Heat: the posaconazole solution was stored in transparent glass in an oven at $40^{\circ} \mathrm{C}$ for 10 days. An aliquot of this solution was diluted with methanol for a concentration of $20 \mu \mathrm{g} \mathrm{mL}^{-1}$, filtered and injected.

Oxidation: hydrogen peroxide solution (3\%) was added into a $25 \mathrm{ml}$ volumetric flask containing $10 \mathrm{ml}$ of a $100 \mu \mathrm{g} \mathrm{mL}$ posaconazole solution. After 10 days in the dark, an aliquot was diluted with methanol until $20 \mu \mathrm{g}$ $\mathrm{mL}^{-1}$.

Acid and alkaline hydrolysis: volumetric flasks containing $10 \mathrm{ml}$ of a $100 \mu \mathrm{g}$ $\mathrm{mL}^{-1}$ posaconazole solution were completed with $0.1 \mathrm{~N} \mathrm{HCl}$ for acidic degradation acid or $0.1 \mathrm{~N} \mathrm{NaOH}$ solution for alkaline degradation and kept at room temperature for 10 days. After this period, an aliquot of each solution was neutralized and diluted with methanol until a final concentration of $20 \mu \mathrm{g}$ $\mathrm{mL}^{-1}$.

\section{Linearity}

Posaconazole reference solutions were prepared in triplicate at concentrations of 5.0, 10.0, 20.0, 30.0, 40.0, 50.0 and $60.0 \mu \mathrm{gL}^{-1}$. Standard plots were constructed and linearity was evaluated statistically by linear regression analysis that was calculated by least-squares regression and analysis of variance (ANOVA).

\section{Precision}

Precision of the method was determined by repeatability (intraday) and intermediate precision (interday). Six sample solutions of posaconazole bulk were prepared at $30 \mu \mathrm{g}$ $\mathrm{mL}^{-1}$ on three different days. The analyses were done in triplicate. 


\section{Accuracy}

The accuracy was determined by the recovery of known amounts of the posaconazole reference standard added to the samples $\left(30 \mu \mathrm{g} \mathrm{mL}{ }^{-1}\right)$. The added amounts were 10, 20 and $25 \mu \mathrm{g} \mathrm{ml}^{-1}$. All solutions were prepared in triplicate.

\section{Robustness}

To access the robustness of the method, three conditions were modified: wavelength of detection, proportion of mobile phase and flow rate. The variations are illustrated in Table 4.

Tab. 4. Conditions used during robustness determination.

\begin{tabular}{lcc}
\hline Condition & Reference & Variation \\
\hline Wavelength $(\mathrm{nm})$ & 260 & $258 ; 262$ \\
Concentration of organic solvent $(\%)$ & 75 & $77 ; 73$ \\
Flow rate $\left.(\mathrm{mL} \mathrm{min})^{-1}\right)$ & 1.0 & $0.8 ; 1.2$ \\
\hline
\end{tabular}

\section{Conclusion}

A simple and rapid HPLC method for quantitative analysis of posaconazole in bulk was developed and validated. The system suitability illustrates good performance and reproducibility of analysis. The degradation product formed under stress oxidative test was well separated from the drug, demonstrating the method is capable of indicating stability.

\section{Acknowledgement}

The authors want to thank the UNIPAMPA-PBDA program.

\section{Authors' Statement}

\section{Competing Interests}

The authors declare no conflict of interest.

\section{References}

[1] Keating GM.

Posaconazole.

Drugs. 2005; 65: 1553-1567.

doi:10.2165/00003495-200565110-00007

[2] Kauffman CA, Malani A, Easley C, Kirkpatrick P.

Posaconazole.

Nat Rev Drug Discovery 2007; 6: 183-184.

doi:10.1038/nrd2270

[3] Thompson GR, Cadena J, Patterson TF.

Overview of antifungal agents.

Clin Chest Med. 2009; 30: 203-215.

doi:10.1016/j.ccm.2009.02.001 
[4] Frampton JE, Scott L.

Posaconazole. A review of its use in the prophylaxis of invasive fungal infections.

Drugs. 2008; 68: 993-1016.

doi:10.2165/00003495-200868070-00008

[5] Kim H, Likhari P, Lin C, Nomeir A.

High-performance liquid chromatographic analysis of the anti-fungal agent $\mathrm{SCH} 56592$ in dog serum.

J Chromatogr B. 2000; 738: 93-98.

doi:10.1016/S0378-4347(99)00489-2

[6] Kim H, Kumari P, Laughlin M, Hilbert M, Indelicato S, Lim J, Lin C, Nomeir A.

Use of high-performance liquid chromatographic and microbiological analysis for evaluating the presence or absence of active metabolites of the antifungal posaconazole in human plasma.

J Chromatogr A. 2003; 987: 243-248.

doi:10.1016/S0021-9673(02)01599-6

[7] Shen J, Krishna G, Hayes R.

A sensitive liquid chromatography and mass spectrometry method for the determination of posaconazole in human plasma.

J Pharm Biomed Anal. 2007; 43: 228-236.

doi:10.1016/j.jpba.2006.06.011

[8] Chhun S, Rey E, Tran A, Lortholary O, Pons G, Jullien V.

Simultaneous quantification of voriconazole and posaconazole in human plasma by high-performance liquid chromatography with ultra-violet detection.

J Chromatogr B. 2007; 852: 223-228.

doi:10.1016/j.jchromb.2007.01.021

[9] Cunliffe J, Noren C, Hayes R, Clement R, Shen J.

A high-throughput LC-MS/MS method for the quantification of posaconazole in human plasma: implementing fused core silica liquid chromatography.

J Pharm Biomed Anal. 2009; 50: 46-52.

doi:10.1016/j.jpba.2009.03.034

[10] Alffenaar JWC, Wessels AMA, van Hateren K, Greijdanus B, Kosterink JG, Uges DRA. Method for therapeutic drug monitoring of azole antifungal drugs in human serum using LC/MS/MS.

J Chromatogr B. 2010; 878: 39-44.

doi: 10.1016/j.jchromb.2009.11.017

[11] Ekiert RJ, Krzec J, Talik P.

Chromatographic and electrophoretic techniques used in the analysis of triazole antifungal agents $-\mathrm{a}$ review.

Talanta. 2010; 82: 1090-1100.

doi:10.1016/j.talanta.2010.06.056

[12] ICH Q2 (R1), International Conference on Harmonization.

Validation of Analytical Procedure: Text and Methodology, 2005.

[13] BRASIL. Agência Nacional de Vigilância Sanitária.

RE 899 - Validação de Métodos Analíticos e Bioanalíticos, 2003.

[14] US Pharmacopoeia XXXI.

US Pharmacopeial Convention, Rockville, MD, 2008.

[15] ICH Q1A (R2), International Conference on Harmonization.

Stability Testing of New Drug Substance and Products: Text and Methodology, 2003. 